\title{
OPTIMUM DURATION OF PERCUTANEOUS TRANSHEPATIC CHOLANGIODRAINAGE IN COMMON BILE DUCT DISEASES COMPLICATED BY OBSTRUCTIVE JAUNDICE
}

DOI: 10.36740/WLek202009205

\author{
Anastasiia L. Sochnieva \\ KHARKIV NATIONAL MEDICAL UNIVERSITY, KHARKIV, UKRAINE
}

\begin{abstract}
The aim: Is to determine the optimum duration of percutaneous transhepatic cholangiodrainage depending on the duration of obstructive jaundice and the baseline total bilirubin level in patients with benign and malignant common bile duct diseases complicated by obstructive jaundice.

Materials and methods: The experience of applying percutaneous transhepatic cholangiodrainage was combined for 88 patients with common bile duct diseases complicated by obstructive jaundice. The patients were divided into three groups: the Group 1 included 15 patients (17.1\%) with benign common bile duct diseases, the Group 2 included 11 patients (12.5\%) with resectable cholangiocarcinomas, and the Group 3 included 62 patients (70.4\%) with unresectable cholangiocarcinomas. To determine optimal terms of biliary decompression using percutaneous transhepatic cholangiodrainage, the Poisson process was applied, and, to be more precise, the quasi-Poisson distribution.

Results: It was found that the reduction of total bilirubin was the fastest in Group 3 patients. It took these patients an average of 7-8 days to reduce total bilirubin to 50 umole/l. In Group 1 patients, the process is somewhat slower. The duration of biliary decompression in this category of patients averages 10-12 days. For Group 2 patients, biliary decompression requires at least 12 days.

Conclusions: Using the Poisson process, or, to be more precise, the quasi-Poisson distribution, we managed to determine the optimum duration of biliary decompression using percutaneous transhepatic cholangiodrainage depending on the obstructive jaundice duration and the baseline total serum bilirubin.
\end{abstract}

KEY WORDS: main bile duct disease, obstructive jaundice, antegrade endobiliary interventions, serum bilirubin level

Wiad Lek. 2020;73(9 p. II):1915-1925

\section{INTRODUCTION}

Hyperbilirubinemia is an integral symptom of biliary hypertension. The latter appears as a result of an increase in serum bilirubin concentration, which in turn is due to the penetration of urine components into blood. When the serum bilirubin level is above $40 \mu$ mole $/$, the clinical signs of obstructive jaundice $(\mathrm{OJ})$ are seen with the naked eye [1].

Pathological changes of liver and other organs and systems are a consequence of disrupted bile outflow. The main cause of hepatocyte necrosis is the progression of dystrophic changes, which leads to the risk of the development of secondary biliary liver cirrhosis. Changes in the histological liver structure, disruption of the intrahepatic blood flow, and, as a consequence, the development of portal hypertension and ascites are observed at late stages of OJ [2].

Hepatic insufficiency as a manifestation of secondary biliary liver cirrhosis at the background of OJ still remains the most frequent and dangerous complication of bile duct diseases and, in at least $50 \%$ of cases, it becomes the cause of lethal outcomes in patients during the post-operative period [3].

Cholestasis contributes to favorable conditions for the development of cholangitis. The most rapid development of irreversible changes in the liver is observed when total obstruction of the common bile duct is combined with the presence of pyoinflammatory processes in bile ducts $[4,5]$.

The cause of bile duct obstruction can be both benign and malignant common bile duct diseases $[6,7]$.

Persistent $\mathrm{OJ}$ is accompanied by headache and skin itching. The above symptoms are due to the toxic influence on the nervous system. The endothelium of brain vessels are affected in case of increased concentration of bilirubin and bile acids in blood. It does not only disrupt cerebral blood circulation and enhances their influence on it, but also entails functional changes in the central nervous system. The liver itself is not able to neutralize the products of nitrogen decomposition (increased ammonia level) formed in large amounts, which intensifies its toxic influence. By reflex, bile acids enhance the tone of the vagus nerve, which is manifested by bradycardia and becomes a sign of blood circulation disorder in case of obstructive jaundice. Moreover, the sinoatrial node is affected by the toxic influence of bile acids. Hypocoagulation disorders of the blood coagulation system take place at the background of inadequate vitamin $\mathrm{K}$ absorption and lead to hemorrhages and hematoma formation. As a result of damaged tubules and glomeruli, water and sodium absorption gets disrupted. The hepatorenal syndrome develops, which is characterized by increased arterial pressure, proteinuria 
and swelling. Disrupted passage of bile to the digestive tract implies the threat of pronounced dysbiotic changes, such as reduced count of anaerobes and increased count of aerobes and opportunistic pathogenic microflora [2].

The main cause of lethal outcomes in OJ is hepatic impairment. Regardless of OJ etiology, the course of hepatic impairment is uniform in all patients. Hepatic impairment is aggravated by the following factors: tumor intoxication, cholangitis, bleeding, general anesthesia, operational trauma. The frequency and severity of post-operative complications directly depend on the grade and duration of hyperbilirubinemia. Serum bilirubin above $200 \mu$ mole/1 is considered hazardous, and above $400 \mu$ mole/l critical for the development of hepatic impairment. An increase in the level of urea and serum creatinine is an adverse prognostic factor [7].

The development of morphological and functional changes in the liver are due to persistent cholestasis and biliary hypertension. The latter lead to the development of hepatic impairment, purulent cholangitis and thrombo-hemorrhagic syndrome. The majority of these patients are aged 60 or older. At this age, the main disease in many patients is accompanied by severe comorbidities that dictate the need for choosing the least traumatic surgical treatment tactics $[8,9]$.

Disturbance of the enteropathic circulation of bile acids, penetration of cholestasis components and their toxic influence on hepatocytes lead to the development of destructive changes in the liver in OJ. The inhibition of cellular respiration, damage of lipid cellular membranes and subcellular structures, disruption of oxidizing phosphorylation processes and destruction of hepatic cells are due to the presence of excessive bound and unbound urine components in blood [2].

Dysproteinemia, disturbance of lipid and carbohydrate metabolism, shift of the electrolyte and acid-base balance, accumulation of toxic metabolism products are responsible for the development of endogenous intoxication and are biochemical signs of hepatocyte damage [10].

Treatment results directly depend on the OJ severity grade. Despite the rapid development of hepatobiliary surgery, there is no unified classification $[11,12,13]$.

Many researchers relate $\mathrm{OJ}$ severity to the baseline serum bilirubin level. Thus, V. Fedorov et al. classify hyperbilirubinemia below $100 \mu$ mole/l as mild OJ, 100-200 $\mu$ mole/l as moderate OJ and above $200 \mu$ mole/l as severe OJ [14].

Other authors use several factors for determining the severity of OJ. Dixon J. M. et al. singled out three independent factors correlating with post-operative complications and mortality: hematocrit below $30 \%$, bilirubin above 200 $\mu$ mole/l and malignant OJ etiology [15].

The proposed classifications and grading scales are rather labor-intensive, detailed and based on complex etiopathogenetic and morphofunctional data that are difficult to apply in clinical practice. The process of assessing OJ severity should be based on clinical signs and generally acceptable laboratory data that can be easily used in the surgeon's everyday practice.
The simplicity of the severity assessment concept is presented in the Child-Pugh classification that is widely used for patients with hepatic cirrhosis. It has become a globally recognized and commonly used severity scale. Unfortunately, this scale cannot be applied for assessing OJ severity $[16,17]$.

The majority of authors believe that, at bilirubin levels below $50 \mu \mathrm{mole} / \mathrm{l}$, an operation does not entail the development of complications $[18,19]$.

A high bilirubinemia level requires measures that are mainly aimed at biliary decompression, resolution of the symptoms of $\mathrm{OJ}$ and its complications, and the prevention of a more severe hepatic insufficiency. Timely treatment of common bile duct diseases complicated by $\mathrm{OJ}$ is still a relevant issue with no definitive solution. Despite the use of mini-invasive interventions, the total serum bilirubin level significantly influences the outcomes and duration of biliary decompression. The introduction of antegrade endobiliary interventions in its turn somewhat facilitated direct access to bile ducts [20,21].

However, there are still no precise recommendations concerning the duration of biliary decompression depending on the duration of OJ and baseline total serum bilirubin in benign and malignant common bile duct diseases complicated by OJ.

\section{THE AIM}

The aim of the study is to define the optimum duration of percutaneous transhepatic cholangiodrainage (PTCD) depending on the duration of obstructive jaundice $(\mathrm{OJ})$ and baseline total serum bilirubin in patients with benign and malignant common bile duct diseases complicated by OJ.

\section{MATERIALS AND METHODS}

During the period from 2011 to 2017, 88 patients with benign and malignant common bile duct diseases complicated by obstructive jaundice underwent percutaneous transhepatic cholangiodrainage (PTCD) at the Surgery Department No. 1 of Kharkiv National Medical University at the clinic of State Institution "Zaycev V.T. Institute of General and Urgent Surgery of the National Academy of Medical Sciences of Ukraine". The causes of obstructive jaundice were the following diseases: choledocholithiasis in 6 patients $(6.8 \%)$, common bile duct strictures in 2 (2.3\%), biliodigestive anastomosis strictures in $7(8 \%)$ and cholangiocarcinomas of various localization in 73 (82.9\%) patients.

The patients' age varied between 33 and 88 years with the mean age being 65 years. There were $34(38.6 \%)$ men and $54(61.4 \%)$ women in both groups.

The patients were divided into three groups: the first group (1) included 15 patients (17.1\%) with benign common bile duct diseases, the second group (2) included 11 patients (12.5\%) with resectable cholangiocarcinomas, and the third group (3) included 62 patients (70.4\%) with unresectable cholangiocarcinomas. 

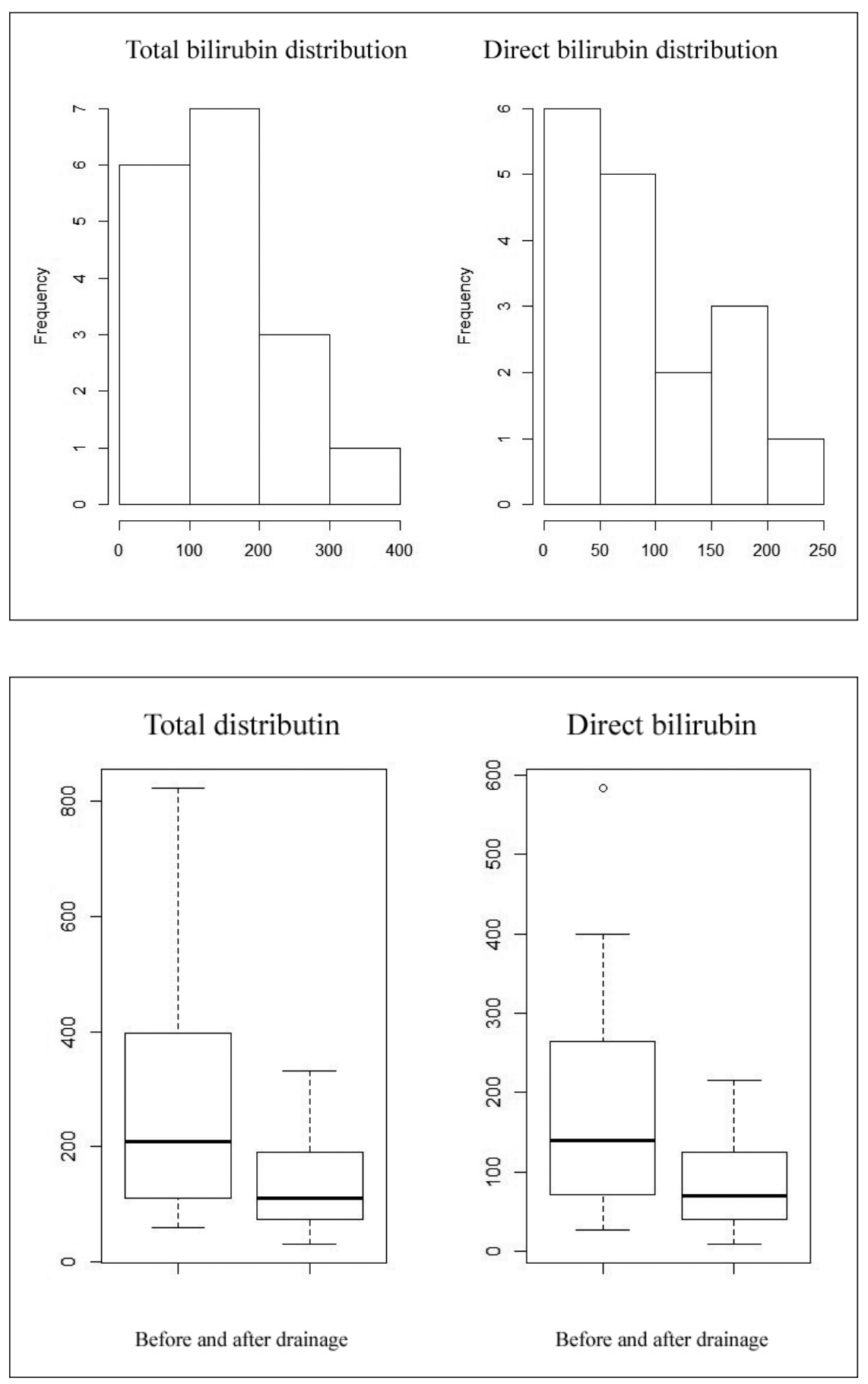

Fig. 1. Distributions of total and direct bilirubin after PTCD in Group 1 patients.
Fig. 2. Mean total and direct bilirubin before and after PTCD in Group 1 patients.
The duration of cholestasis was determined according to O.V. Smirnov's (1974) classification. Acute OJ was observed in 38 patients (43.2\%), whereas acute prolonged and chronic OJ was observed in 11 (12.5\%) and 39 (44.3\%) patients, respectively.

The patients were distributed in terms of the total serum bilirubin level: $43-150 \mu$ mole/l -14 patients (15.9\%), 150-

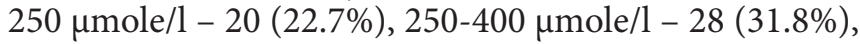
more than $400 \mu$ mole/l - 26 (29.6\%) patients.

The study profile was in conformity with the CONSORT international requirements and had a respective study design of retrospective and prospective randomized clinical trial. The study was authorized by the ethical committee of Kharkiv National Medical University (meeting minutes No. 3 dated 03.04.2019). All ethical principles have been observed. Attached is the expert opinion regarding the authorization to publish materials in the press and other mass media. All patients gave an informed consent for their treatment results to be used for research purposes.

In order to determine optimum terms of biliary decompression using antegrade endobiliary interventions, namely PTCD, we decided to apply the Poisson process, and, to be more precise, the quasi-Poisson distribution that reflects the process of total serum bilirubin reduction $[23,24,25,26,27,28]$. The latter reflects the duration of biliary decompression taking into account the variable 


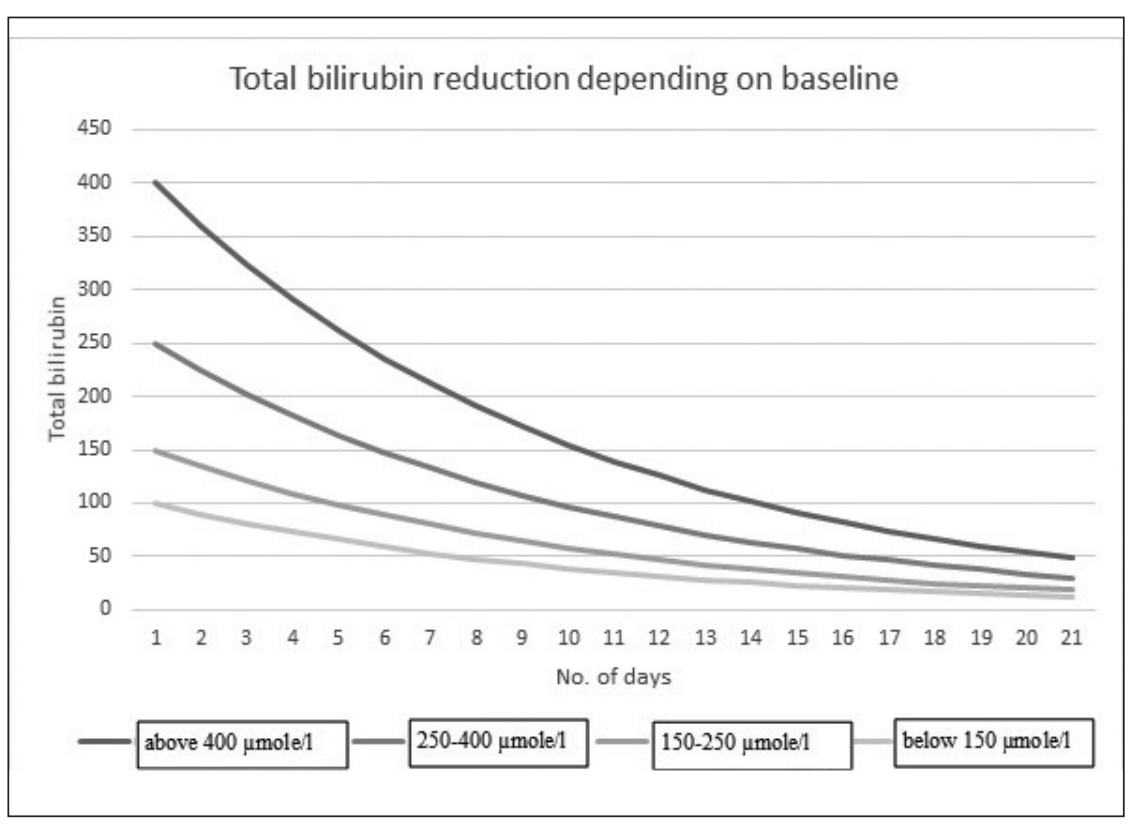

Fig. 3. Plots of total bilirubin reduction with time as compared to baseline in Group 1 patients.
- the bilirubin level after drainage with respect of time whose value was $\log$-transformed: (log(total bilirubin/ duration of cholangiodrainage)). The choice of the model for predicting the process of bilirubin reduction based on quasi-Poisson model is explained by the fact that the dispersion and the mean are equal in the Poisson distribution, whereas excessive dispersion was observed in our case. The distributions of total and direct bilirubin were checked against the difference of dispersion and the mean. The difference was significant, so a regression model based on quasi-Poisson distribution was selected for analysis. Using the R software environment, a regression model was built and regression equality coefficients were analyzed, which allowed us to determine mean durations of biliary decompression depending on $\mathrm{OJ}$ duration and total serum bilirubin level.

Statistical processing of digital data was performed on a personal computer using Excel 2010, SPSS and R - free statistical software. The representativeness of the findings were assessed based on the Mann-Whitney test, Student's t-test and the $\chi 2$ test, confidence intervals were calculated using the Clopper-Pearson method. The results were considered statistically significant at $\mathrm{p}<0.05$.

\section{RESULTS}

Within the first two days after admission, all patients with benign and malignant common bile duct diseases underwent PTCD under X-ray or ultrasound navigation with the purpose of biliary decompression. Cholangiodrainage was inserted for $12(13.6 \%)$ patients with moderately dilated intrahepatic ducts $(<5 \mathrm{~mm})$.

Subsequently, $16(18.2 \%)$ patients underwent reconstructive-reparative surgeries, including 5 (5.7\%) for choledocholithiasis, 11 (12.5\%) for cholangiocarcinomas of various localization, and another $2(2.3 \%)$ patients underwent mini-invasive interventions with combined antegrade and retrograde access in the case of "endoscopically complicated forms" of choledocholithiasis. In the rest of the patients, antegrade endobiliary interventions were the only treatment manipulation, including 8 (9.1\%) patients with benign common bile duct diseases due to their sufficiency or a high anesthetic and operative risk and severity of comorbidities and 62 (70.4\%) patients with unresectable cholangiocarcinomas.

The process of bilirubin reduction in Group 1 patients was considered to be changing according to a Poisson process [23-28]. In this group of patients, total bilirubin levels reduced with time as follows: average total bilirubin was $267.9 \mu$ mole/l before biliary decompression, and 139.24 $\mu$ mole/l after treatment. The arithmetic mean of the difference is $128.7 \mu \mathrm{mole} / \mathrm{l}(\mathrm{p}<0.001)$. Direct bilirubin decreased from $182.84 \mu$ mole/l to $87.55 \mu$ mole/l with the arithmetic mean of the difference being $95.3 \mu$ mole $/ 1(p<0.001)$. However, the rate of total and direct bilirubin reduction is not linear as, in most cases, bilirubin significantly decreases during the first day, and the process slows down later.

The distribution of bilirubin levels after treatment for a sample population of patients demonstrates pronounced asymmetry. (Fig. 1 shows distributions of total and direct bilirubin, and Fig. 2 shows differences of means before and after PTCD).

The distributions of total and direct bilirubin in Group 1 patients were checked for the difference of dispersion and the mean. The difference was significant, so the quasi-Poisson distribution was selected for analysis [23-28].

The reduction rate also depends on $\mathrm{OJ}$ duration: the rate is higher for acute $\mathrm{OJ}$ and lower for acute prolonged jaundice, and on the baseline bilirubin level: the rate is higher at bilirubin levels of 250-400 $\mu$ mole/l than at levels below $150 \mu \mathrm{mole} / \mathrm{l}$. Therefore, in order to establish the correlation between the bilirubin level after PTCD and the number of drainage days, $\mathrm{OJ}$ duration and baseline bilirubin, a logarithmic function was applied rather than a linear one. 
Table I. Recommended duration of biliary decompression for patients with benign common bile ducts diseases following PTCD

\begin{tabular}{cc}
\hline $\begin{array}{c}\text { Baseline total bilirubin } \\
(\boldsymbol{\mu} \text { mole/l) }\end{array}$ & $\begin{array}{c}\text { Duration of } \\
\text { cholangiodrainage } \\
\text { (days) }\end{array}$ \\
\hline below $150 \mu \mathrm{mole} / \mathrm{l}$ & $7-9$ \\
\hline $150-250 \mu \mathrm{mole} / \mathrm{l}$ & $11-13$ \\
\hline $250-400 \mu \mathrm{mole} / \mathrm{l}$ & $15-17$ \\
\hline above $400 \mu \mathrm{mole} / \mathrm{l}$ & more than 20 \\
\hline
\end{tabular}

On average, in Group 1 patients with chronic OJ and total bilirubin below $150 \mu$ mole/l, its final level was 25.5 $\mu$ mole/l. Every day, total bilirubin will decrease by $10 \%$. Thus, in case of baseline bilirubin level below $150 \mu$ mole/l, the reduction of bilirubin to this level will take 14 days.

If a patient's total bilirubin level is 150-250 $\mu$ mole/l with chronic OJ, the final total bilirubin level will be 51.85 $\mu$ mole/l after the same period of time as for the patients with a bilirubin level below $150 \mu$ mole/l. If a patient's total bilirubin level is $250-400 \mu$ mole/l, the mean bilirubin level after the first day after cholangiodrainage will be 62.24 $\mu \mathrm{mole} / \mathrm{l}$, and it will be $152.16 \mu \mathrm{mole} / \mathrm{l}$ at a level above 400 $\mu \mathrm{mole} / \mathrm{l}$. (Figure 3 shows plots of total bilirubin reduction with time as compared to baseline in Group 1 patients).

For patients with acute OJ, the total bilirubin level after PTCD is somewhat higher than for patients with a bilirubin level below $150 \mu$ mole $/ 1(26.18 \mu$ mole $/ 1)$, whereas it is somewhat lower for patients with acute prolonged OJ $(16.12$ $\mu$ mole/l). However, the reduction rate for different forms does not essentially differ. The process of direct bilirubin reduction is the same as for total bilirubin.

Thus, based on the conducted analysis, the duration of PTCD-based biliary decompression that is optimum for patients with benign and malignant common bile duct diseases complicated by OJ was estimated. For these patients, the duration averaged 10-12 days since, irrespective of the baseline total bilirubin level, it decreases by an average of $10 \%$ per day. (Table I includes mean durations (number
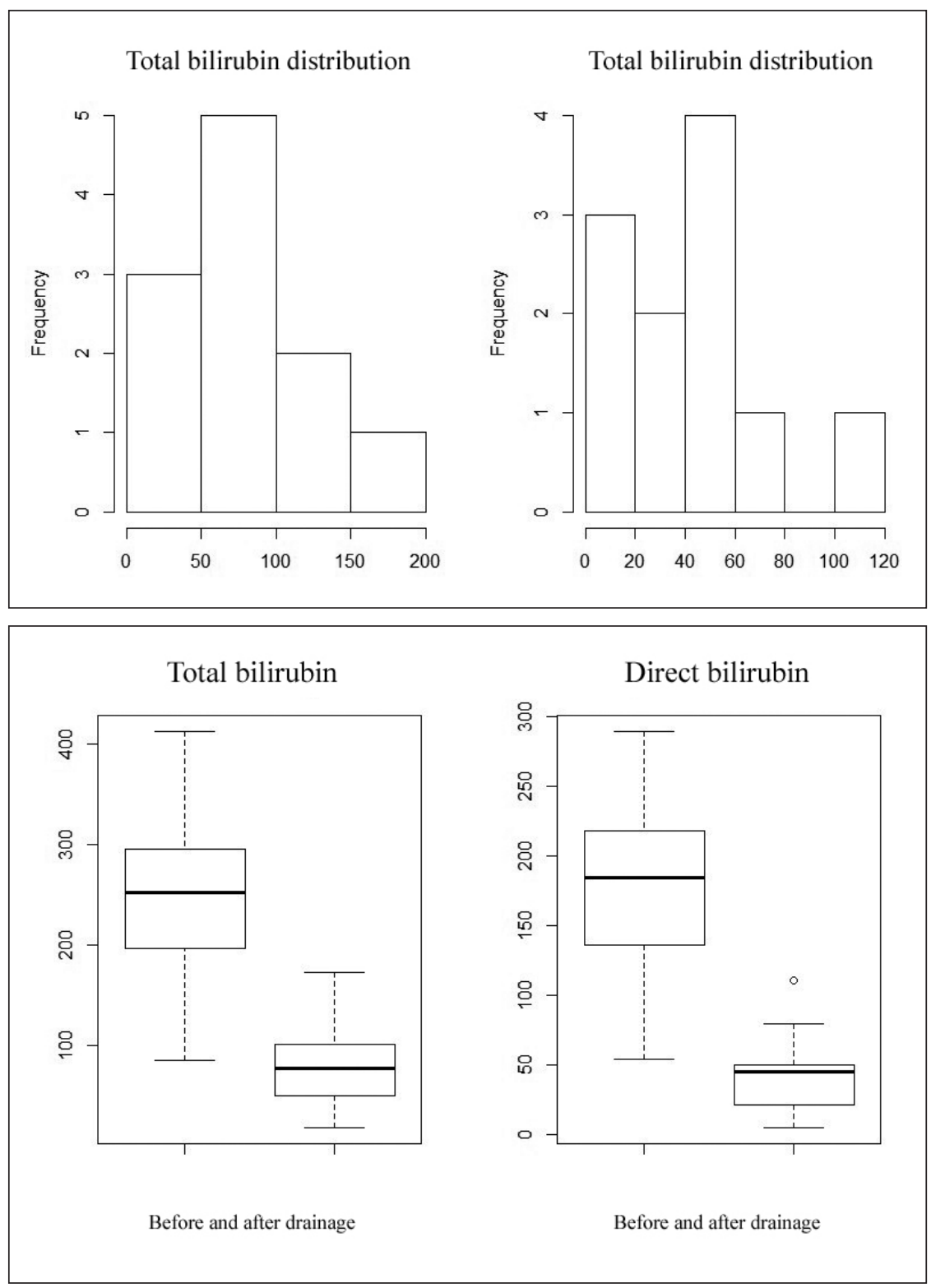

Fig. 4. Distributions of total and direct bilirubin after PTCD in Group 2 patients.

Fig. 5. Distribution of mean total and direct bilirubin before and after PTCD in Group 2 patients. 


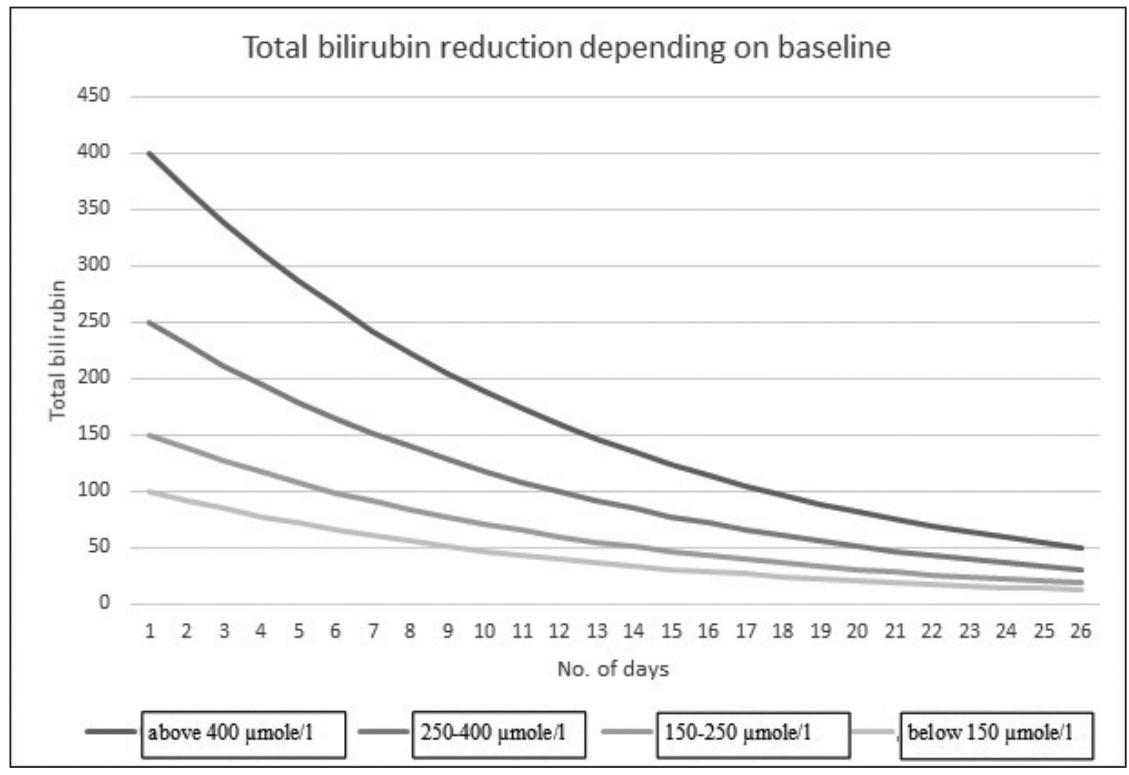

Fig. 6. Plots of total bilirubin reduction with time as compared to baseline in Group 2 patients. of days) of PTCD that brings the bilirubin level below 50 $\mu$ mole/l). However, it should be noted that total bilirubin should be controlled in the process of treatment, especially at the final stage.

The use of PTCD was analyzed in Group 2 patients. The process of total bilirubin reduction during biliary decompression using PTCD in Group 2 patients, just like in Group 1 patients, was considered to be changing according to a Poisson process [23-28].

In Group 2 patients, total bilirubin levels during biliary decompression reduced with time as follows: average total bilirubin was $243 \mu$ mole/l before treatment and 78.56 $\mu$ mole/l after treatment. The arithmetic mean of the difference is $164.26 \mu \mathrm{mole} / \mathrm{l}$ with the difference being significant at $\mathrm{p}<0.001$. Direct bilirubin decreased from $172.76 \mu$ mole $/ 1$ to $44.22 \mu \mathrm{mole} / \mathrm{l}$ with the arithmetic mean of the difference being $128.55 \mu$ mole $/ \mathrm{l}(\mathrm{p}<0.001)$.

The distribution of bilirubin levels after treatment for patients from subgroup 2A demonstrates pronounced asymmetry. (Fig. 4 shows distributions of total and direct bilirubin, and Fig. 5 shows differences of means before and after PTCD).

The distributions of total and direct bilirubin in Group 2 patients were checked for the difference of dispersion and the mean. The difference was significant, so the quasi-Poisson distribution was selected for analysis [23-28].

On average, in Group 2 patients with chronic OJ and total bilirubin below $150 \mu \mathrm{mole} / \mathrm{l}$, its final level was $8.35 \mu \mathrm{mole} / \mathrm{l}$. Every day, total bilirubin will decrease by $8 \%$. Thus, in case of baseline bilirubin level below $150 \mu$ mole/l, the reduction of bilirubin to this level will take 12 days.

If the total bilirubin level of a patient with chronic $\mathrm{OJ}$ is 150-250 $\mu$ mole/l, the final total bilirubin level will be 23.38 $\mu$ mole/l after the same period of time as for the patients with a bilirubin level below $150 \mu$ mole/l. If a patient's total bilirubin level is $250-400 \mu$ mole/l, the mean bilirubin level after the first day after cholangiodrainage will be $19.28 \mu$ mole/l, and it will be $26.3 \mu \mathrm{mole} / \mathrm{l}$ at a level above $400 \mu \mathrm{mole} / \mathrm{l}$.
It was found that the total bilirubin level depends only on the duration of biliary decompression, and not on its baseline level. The difference between total bilirubin levels is not high, so the duration of PTCD will not differ significantly for Group 2 patients with different baseline levels. (Figure 6 shows plots of total bilirubin reduction with time as compared to baseline total serum bilirubin).

Total bilirubin after PTCD is somewhat higher for patients with acute $\mathrm{OJ}$ than for patients with total bilirubin below $150 \mu$ mole/l $(8.76 \mu$ mole/l) and twice as high for patients with acute prolonged $\mathrm{OJ}(16.03 \mu \mathrm{mole} / \mathrm{l})$. However, the reduction rate does not differ essentially depending on the duration of OJ. Therefore, total bilirubin should be controlled individually for each patient when performing biliary decompression. The reduction process of direct bilirubin is the same as for total bilirubin, but its reduction is somewhat faster; it was found however that the influence of OJ duration and baseline total bilirubin is not significant. (Table II shows recommended durations of biliary decompression using PTCD in resectable cholangiocarcinomas prior to a reconstructive-reparative operative intervention).

However, these values may be adjusted depending on the direct bilirubin reduction rate and be 2-3 days less since the reduction rate of direct bilirubin is somewhat lower than that of total bilirubin.

We have singled out a third group of patients who had knowingly unresectable common bile tumors and underwent PTCD as the only treatment manipulation or in combination with endobiliary stenting. These patients were divided into subgroups: patients with knowingly unresectable tumor processes who were inserted an external-internal PTCD - Subgroup 3A including 36 (58.1\%) patients, and those who were inserted an external PTCD - Subgroup 3B including 26 (41.9\%) patients.

The process of bilirubin reduction in Group 3 patients, just like in patients of two previous groups, is considered to be changing according to a Poisson process [23-28]. 
Table II. Recommended duration of biliary decompression using PTCD for patients with resectable cholangiocarcinomas

\begin{tabular}{cc}
\hline $\begin{array}{c}\text { Baseline total bilirubin } \\
(\boldsymbol{\mu m o l e} / \mathrm{l})\end{array}$ & $\begin{array}{c}\text { Duration of cholangiodrainage } \\
\text { (days) }\end{array}$ \\
\hline below $150 \mu \mathrm{mole} / \mathrm{l}$ & $9-10$ \\
\hline $150-250 \mu \mathrm{mole} / \mathrm{l}$ & $13-14$ \\
\hline $250-400 \mu \mathrm{mole} / \mathrm{l}$ & $19-21$ \\
\hline above $400 \mu \mathrm{mole} / \mathrm{l}$ & More than 25 \\
\hline
\end{tabular}

In Subgroup 3A patients, total bilirubin levels reduced with time as follows: average total bilirubin was $324.17 \mu \mathrm{mole} / \mathrm{l}$ before treatment and $240.42 \mu$ mole/l after treatment. The arithmetic mean of the difference is $83.75 \mu$ mole/l with the difference being significant at $\mathrm{p}=0.001$. Direct bilirubin decreased from $219.45 \mu$ mole/l to $161.76 \mu$ mole/l with the arithmetic mean of the difference being $62.67 \mu$ mole $/ 1(p=0.001)$.

The distribution of total bilirubin levels after treatment for patients from subgroup 3A demonstrates pronounced asymmetry. (Fig. 7 shows distributions of total and direct bilirubin, and Fig. 8 shows differences of means before and after PTCD).

The distributions of total and direct bilirubin in Subgroup $3 \mathrm{~A}$ patients were checked for the difference of dispersion and the mean using a quasi-Poisson distribution [23-28].

On average, in Subgroup 3A patients with chronic OJ and total bilirubin below $150 \mu$ mole/l, its final level was $20.76 \mu \mathrm{mole} / \mathrm{l}$. Every day, total bilirubin will decrease by
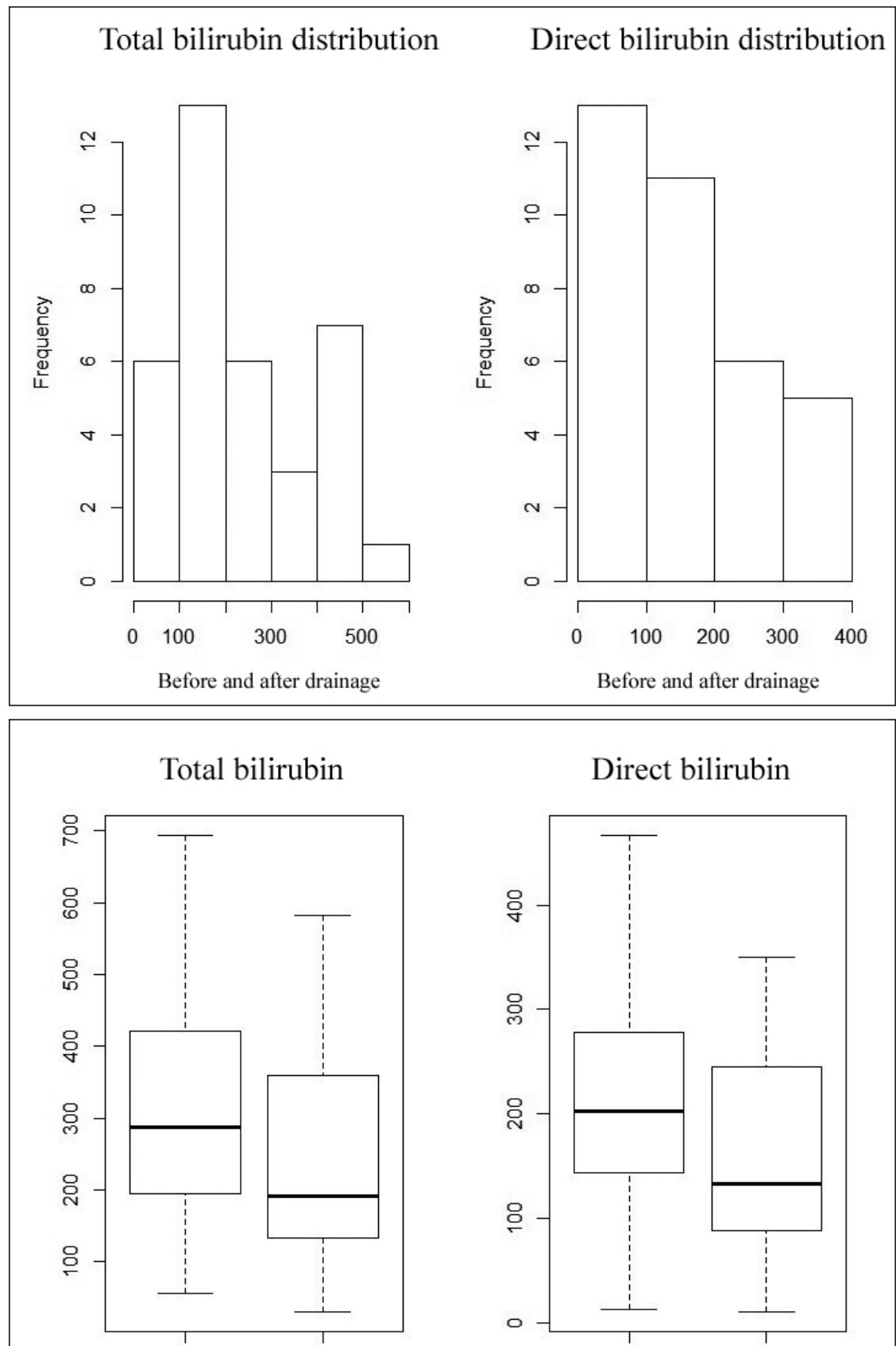

Before and after drainage
Direct bilirubin

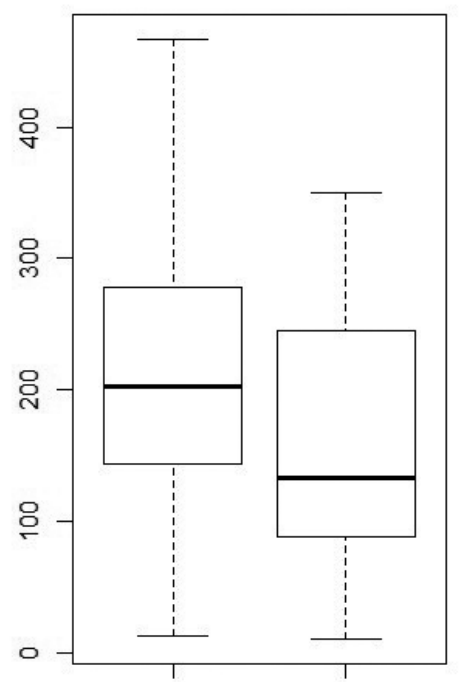

Before and after drainage
Fig. 7. Distributions of total and direct bilirubin after PTCD in Subgroup 3A patients.
Fig. 8. Mean total and direct bilirubin levels before and after PTCD in Subgroup 3A patients. 


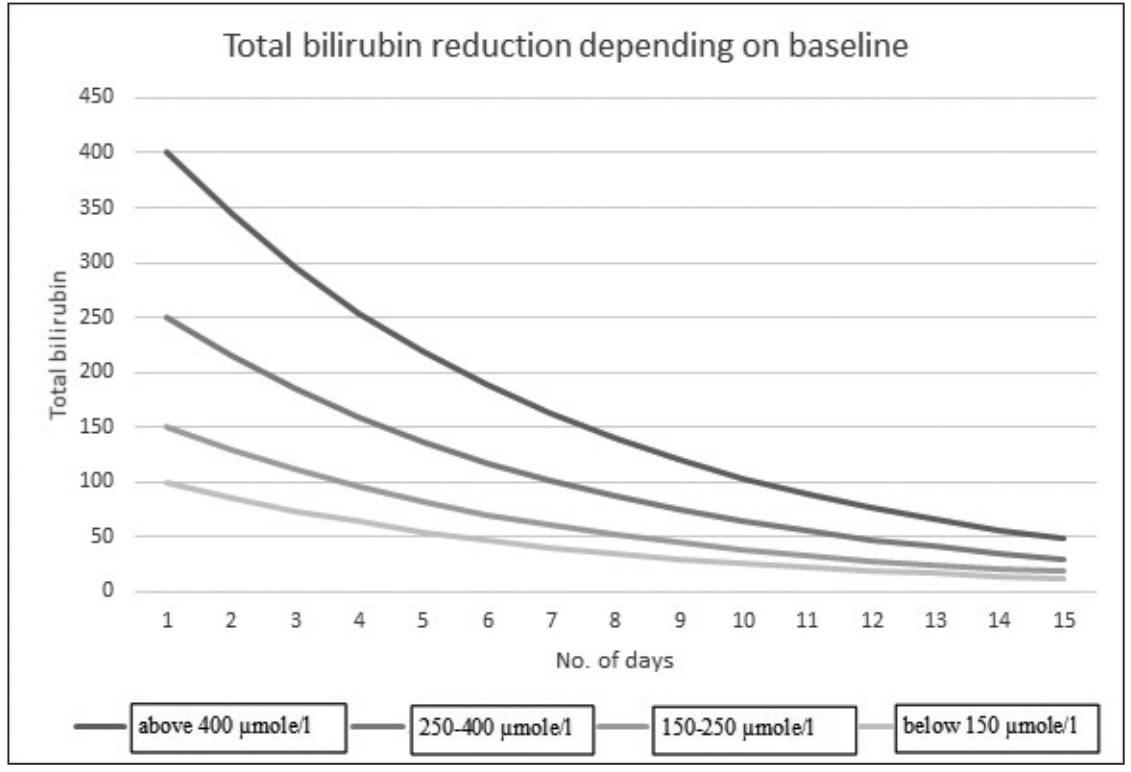

Fig. 9. Plots of total bilirubin reduction with time depending on baseline total bilirubin in Subgroup 3 A patients.
$14 \%$. Thus, in case of baseline bilirubin level below 150 $\mu$ mole/l, the reduction of bilirubin to this level will take around 12 days.

If the total bilirubin level of a patient with chronic $\mathrm{OJ}$ is $150-250 \mu \mathrm{mole} / \mathrm{l}$, the final total bilirubin level will be 71.28 $\mu$ mole/l after the same period of time as for the patients with a bilirubin level below $150 \mu$ mole/l. If a patient's total bilirubin level is $250-400 \mu \mathrm{mole} / \mathrm{l}$, the mean bilirubin level after the first day after cholangiodrainage will be 120.75 $\mu$ mole/l, and it will be $185.83 \mu$ mole/l at a level above 400 $\mu$ mole/l. (Figure 9 shows plots of total bilirubin reduction with time depending on baseline total bilirubin in Subgroup 3A patients).

Total bilirubin after PTCD is somewhat higher for patients with acute $\mathrm{OJ}$ than for patients with total bilirubin below $150 \mu$ mole/l $(17.92 \mu$ mole/l) or for patients with acute prolonged OJ $(18.66 \mu$ mole/l). However, the reduction rate does not differ essentially depending on the duration of OJ. The reduction process of direct bilirubin is the same as for total bilirubin.

Thus, based on the conducted analysis, the optimum duration of biliary decompression for total bilirubin reduction through the insertion of an external-internal PTCD was estimated for patients with unresectable cholangiocarcinomas. For these patients, the duration averaged 7 days since, irrespective of the baseline total bilirubin level, it decreases by an average of $14 \%$ per day. (Table III includes mean durations of biliary decompression that brings the bilirubin level below $50 \mu \mathrm{mole} / \mathrm{l})$. However, it should be noted that total bilirubin should be controlled in the process of biliary decompression, especially at the final stage.

The reduction of total bilirubin in Subgroup 3B patients was similar, total and direct bilirubin decreased by around 13-14\% per day, but final bilirubin levels were somewhat higher than in Subgroup 3A patients after the same period of time (though the difference is not significant). (Figures 10-11 show distributions of total and direct bilirubin after PTCD and the difference between mean total and direct bilirubin before and after PTCD in Subgroup 3B patients. Figure 12 shows plots of total bilirubin reduction depending on its baseline level. Table IV provides recommended durations of biliary decompression through the insertion of an external PTCD for patients with unresectable cholangiocarcinomas).

For these patients, the mean duration of biliary decompression is 8 days since total bilirubin decreases by an average of $13-14 \%$ per day regardless of its baseline level.

\section{DISCUSSION}

Since no methods have been found in the available literature to determine the optimal duration of bile duct de-

Table III. Recommended duration of biliary decompression through the insertion of an external-internal PTCD for patients with unresectable cholangiocarcinomas

\begin{tabular}{cc}
\hline $\begin{array}{c}\text { Baseline total bilirubin } \\
(\boldsymbol{\mu} \mathrm{mole} / \mathrm{l})\end{array}$ & $\begin{array}{c}\text { Duration of cholangiodrainage } \\
\text { (days) }\end{array}$ \\
\hline below $150 \mu \mathrm{mole} / \mathrm{l}$ & $5-6$ \\
\hline $150-250 \mu \mathrm{mole} / \mathrm{l}$ & $8-10$ \\
\hline $250-400 \mu \mathrm{mole} / \mathrm{l}$ & $11-12$ \\
\hline above $400 \mu \mathrm{mole} / \mathrm{l}$ & More than 15 \\
\hline
\end{tabular}

Table IV. Recommended duration of biliary decompression through the insertion of an external PTCD for patients with unresectable cholangiocarcinomas

\begin{tabular}{cc}
\hline $\begin{array}{c}\text { Baseline total bilirubin } \\
(\boldsymbol{\mu} \mathrm{mole} / \mathrm{l})\end{array}$ & $\begin{array}{c}\text { Duration of cholangiodrainage } \\
\text { (days) }\end{array}$ \\
\hline below $150 \mu \mathrm{mole} / \mathrm{l}$ & $5-7$ \\
\hline $150-250 \mu \mathrm{mole} / \mathrm{l}$ & $9-11$ \\
\hline $250-400 \mu \mathrm{mole} / \mathrm{l}$ & $12-13$ \\
\hline above $400 \mu \mathrm{mole} / \mathrm{l}$ & More than 16 \\
\hline
\end{tabular}



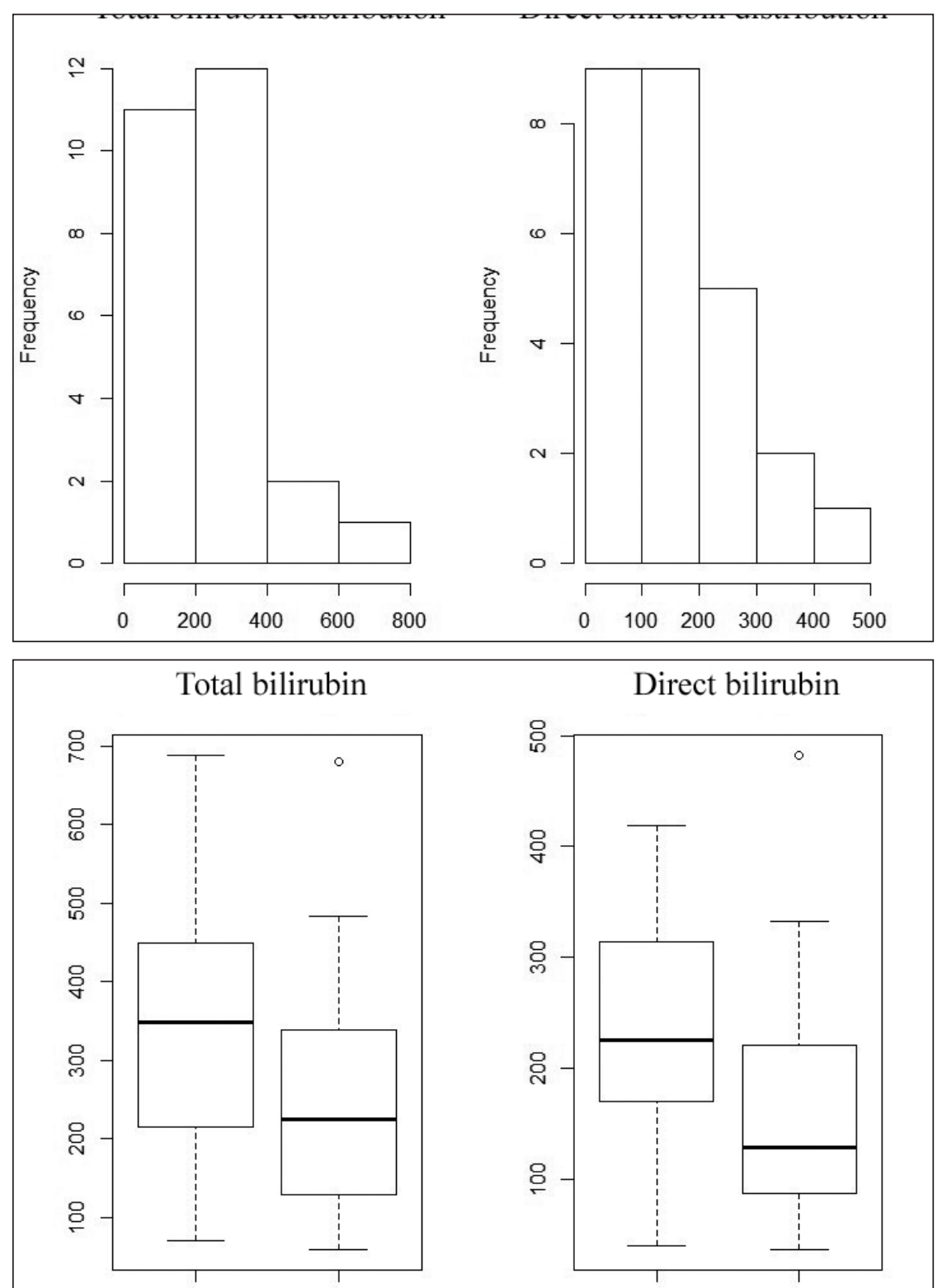

Before and after drainage
Direct bilirubin

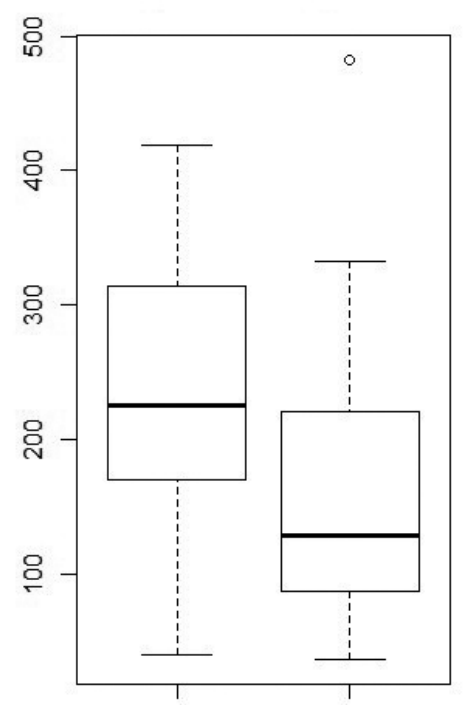

Before and after drainage
Fig. 10. Distributions of total and direct bilirubin after PTCD in Subgroup 3B patients.
Fig. 11. Distributions of mean total and direct bilirubin levels after PTCD in Subgroup 3B patients. compression, it was decided to apply the Poisson process, and, to be more precise, the quasi-Poisson distribution that reflects the process of total serum bilirubin reduction [23 - 28].

Found that the process of reducing serum total bilirubin is not linear but logarithmic function, which in turn causes first a rapid decrease in its level and then slow down the process of biliary decompression.

The use of the logarithmic function to determine the optimal timing of biliary decompression is also due to the fact that the process of reducing total serum bilirubin depends not only on its initial level but also on the duration of mechanical jaundice - the longer jaundice, the lower the rate of reduction of total bilirubin.

However, it should be noted that, for example, in patients with benign common bile duct diseases, in principle, the rate of decrease in total bilirubin does not differ depend- ing on the duration of OJ. The process of reducing direct bilirubin is the same as the total. Regardless of the initial level of total bilirubin in patients with benign common bile duct diseases, the last one decreases by an average of $10 \%$ per day.

The process of reducing total bilirubin is somewhat slower in patients with resectable malignant common bile duct diseases, in whom PTCD is used as a preoperative preparation for reconstructive surgery - each day the bilirubin will be less by $8 \%$ than in the previous one. Because the duration of PTCD for patients with resectable malignant common bile duct diseases does not differ significantly depending on the initial level of total bilirubin and the duration of OJ, it is advisable to monitor the level of both total and direct bilirubin. It is determined that the process of reducing direct bilirubin is the same as the total, but its reduction is somewhat faster. This fact should be 


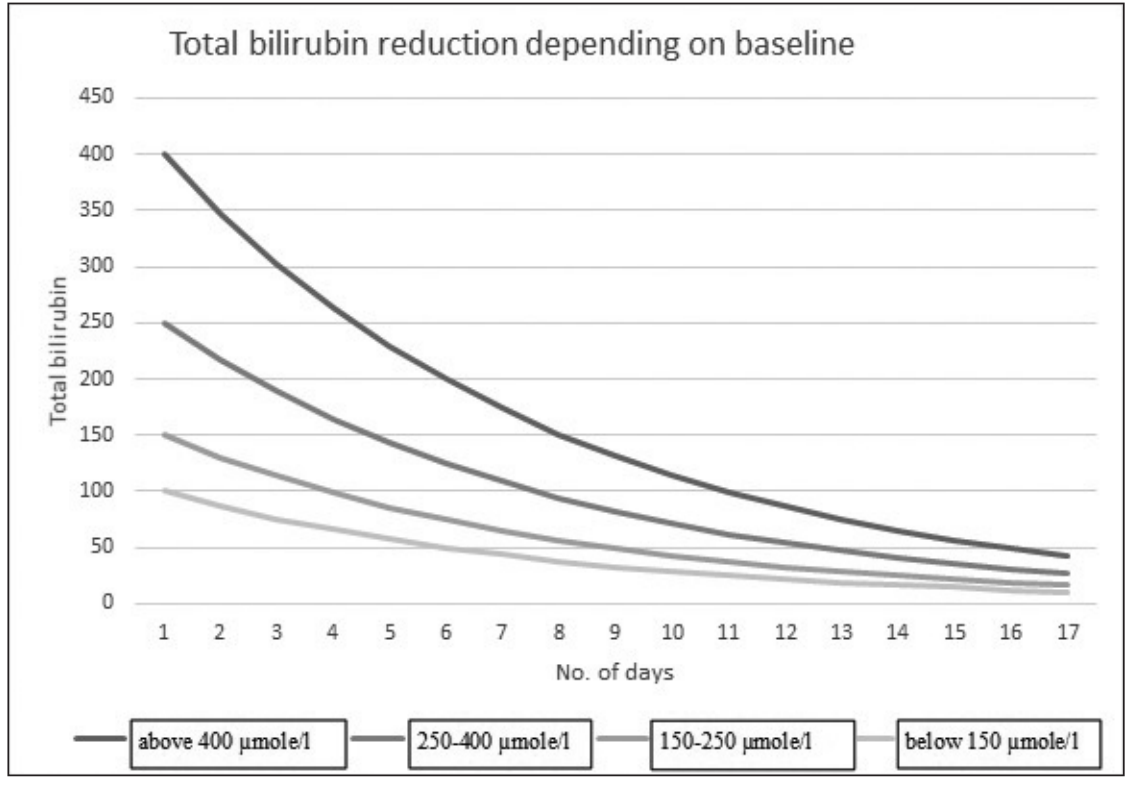

Fig. 12. Plots of total bilirubin reduction with time depending on baseline total bilirubin in Subgroup 3 B patients considered as under this term biliary decompression can be adjusted depending on the speed reduction of direct bilirubin and be less for 2-3 days.

The fastest rates of reduction of total bilirubin are in patients with unresectable malignant common bile duct diseases, in which the latter is reduced by $13-14 \%$ per day. In this category of patients, the rate of decrease in total bilirubin depending on the duration of $\mathrm{OJ}$ is not fundamentally different, but significantly depends on the initial level of total bilirubin. The process of reducing direct bilirubin is the same as total regardless of the type of PTCD, which in turn does not affect the duration of biliary decompression when using external-internal PTCD, which is physiological than external PTCD.

The developed prognostic model significantly increases the economic effect of the study, because with adequate setting and functioning of PTCD does not need to monitor the level of total serum bilirubin every day. It is advisable to focus on certain laboratory parameters at the final stage of biliary decompression in patients with common bile duct diseases complicated by mechanical jaundice.

\section{CONCLUSIONS}

Taking the above into consideration, it may be concluded that the process of total bilirubin reduction was the fastest in Group 3 patients. These patients take on average 8 days to reduce total bilirubin to the desired level, but the duration of biliary decompression depends significantly on baseline total bilirubin level.

The process is somewhat slower for Group 1 patients, but the final outcome also depends considerably on the baseline total bilirubin level. The duration of biliary decompression for this category of patients is on average 10-12 days.

Group 2 patients need at least 12 days for biliary decompression, but the outcome does not significantly depend on baseline total bilirubin level and OJ duration. The direct bilirubin level needs to be constantly controlled in these patients.

\section{REFERENCES}

1. Galperin E.I., Kotovskiy A.E., Momunova 0.N. Optimum bilirubinemia level before surgeries in patients with obstructive jaundice of tumor etiology. Annals of surgical hepatology. 2011; 1: 45-51.

2. Nychytailo M.Yu., Hodlevskyi A.I., Savoliuk S.I. et al. Metabolic changes and justification of the principles of pre-operative treatment of patients with non-tumor obturative obstructivejaundice depending on the baseline level of hepatic dysfunction. Ukrainian Journal of Surgery. 2011; 5(14): 48-54.

3. Starosek V.N., Khilko S.S., Vlakhov A.K. Current trends of surgical treatment of patients with obturative jaundice complicated by hepatic insufficiency. Clinical Surgery. 2009; 4: 15-18.

4. Datsenko B.M. Obturative jaundice - the pathogenic basis for the development of purulent cholangitis and biliary sepsis. Bulletin of Vinnytsia National Medical University. 2010; 14(1): 15-19.

5. Kondratenko P.G., Tsarulkov Yu.A., Hurianov V.G. Mortality in acute cholangitis: factorial analysis and ways to reduce the risk of lethal outcome. Ukrainian Journal of Surgery. 2009; 5: 115-120.

6. Kotiv B.N., Dzidzava I.I., Smorodskiy A.V. et al. Surgical tactics in nontumor obstructive jaundice. Current issues of surgical hepatology; congress materials. Donetsk, 2013; 110.

7. Stoiko Yu.M., Levchuk A.L., Bardakov V.G., Vetshev P.S. The potential of modern diagnostics methods and justification of therapeutic tactics in obstructive jaundice. Bulletin of Surgical Gastroenterology. 2008;2: 24-32.

8. Galperin E.I., Akhaladze G.G., Kotovskiy A.E. et al. Pathogenesis in the treatment of acute purulent cholangitis. Annals of Surgical Hepatology. 2009; 14(4): 13-21.

9. Galperin E.I. Obstructive jaundice: the condition of "false stability", consequences of the "second shock", treatment principles. Annals of Surgical Hepatology. 2011; 16(3): 16-26.

10. Suda K., Ohtsuka M., Ambiry S. et al. Risk factors of liver dysfunction after extended hepatic resection in biliary tract malignancies. Am. J. Surg. 2009; 197(6):752-758; D01:10.1016/j.amjsurg.2008.05.007

11. Nikfarjam M., Staveley-0'Carroll K.F., Kimchi E.T., Hardacre J.M. Pancreaticoduodenectomy in patients with a history of Roux-en Y gastric bypass surgery. JOP. 2009; 10: 169-73.

12. Saidi R.F., Elias N., Ko D.S., Kawai YT., Markmann J., Cosimi A.B., Hertl M. Biliary reconstruction and complications after living-donor liver transplantation. HPB (0xford). 2009; 11: 505-509. 
13. Galperin E.I., Momunova 0.N. Classification of obstructive jaundice severity. Surgery. 2014; 3:406-408.

14. Fedorov V.D., Vishnevskiy V.A., Kubyshkin V.A. et al. Surgical treatment of common bile duct cancer. Kremlin Medicine. Clinical Bulletin. 2000; 2: 13-17.

15. Dixon J.M., Armstrong C.P., Duffy S.W., Davies G.C. Factors affecting morbidity and mortality after surgery for obstructive jaundice: a review of 373 patients. Gut. 1983. 24; (9):845-852.

16. Child C.G., Turcotte J.G., Surgery and portal hypertension // In: The liver and portal hypertension. Ed. Child C.G. Philadelfia: Saunders. 1964:50-64.

17. Pugh R.N., Murray-Lyon I.M., Dawson J.L. et al. Transection of the oesophagus for bleeding oesophagal varices. Br. J. Surg. 1973. 60; (8): 646-649.

18. Smith R.A., Dajani K., Dodd S. et al. Preoperative Resolution of Jaundice Following Biliary Stenting Predicts More Favourable Early Survival in Resected Pancreatic Ductal Adenocarcinoma. Ann. Surg. Oncol. 2009; 15. (11): 3138-3146.

19. Takahashi T., Togo S., Tanaka K. et al. Safe and Permissible Limits of hepatectomy in Obstructive Jaundice Patients. WId J. Surg. 2008; 28: 475-481.

20. Bebezov Kh.S., Osmonov T.A., Bebezov B.Kh. The results of percutaneous transhepatic endobiliary interventions in the bile duct surgery. Annals of Surgical Hepatology. 2006; 4: 51.

21. Kryshen V.P., Ryazanov D.Yu., Kudriavtseva V.E. Methods of optimizing the treatment and diagnostic tactics in patients with non-tumor obturative jaundice. Gastroenterology. 2015; 2: 18-56.

22. Smirnov Ye.V. Surgical operations on bile ducts. Moscow. 1974: 238.

23. Shitikov V.K., Mastitskiy S.E. Classification, regression and other Data Mining algorithms using R. 2017. 8.4.

24. Robert I. Kabacoff. R in Action. Data Analysis and Graphics with R. 2011: 472 .

25. Ponarin E.D., Lisovskiy A.V., Zelikova Yu.A. Models for Poisson dependent variables: can the results of football matches be predicted? Sociology: 4M. 2013; 36: 36-64;
26. Petrie A., Sabin K. Medical statistics at a glance: textbook, trans. from English. Ed. By V.P. Leonov. - 3rd edition, amended and revised. Geotar-Media. 2015: 216.

27. Vahedi M., Pourhoseingholi A., Ashtari S., Pourhoseingholi M.A. et al. Using statistical models to assess medical cost of hepatitis $($ virus. Gastroenterol Hepatol Bed Bench. 2012; 5(1): 31-36.

28. Warner P. Poisson regression. J Fam Plann Reprod Health Care 2015;41:223-224. doi:10.1136/jfprhc-2015-101262.

ORCID and contributionship:

Anastasiia L. Sochnieva: 0000-0003-0106-5247 A, B, C, D, E, F

\section{Conflict of interest:}

The Author declare no conflict of interest.

\section{CORRESPONDING AUTHOR Anastasiia L. Sochnieva \\ Kharkiv National Medical University \\ 4 Nauky Ave., 61000 Kharkiv, Ukraine \\ tel: +38099-770-75-20, \\ e-mail: sochnevanastya@gmail.com}

Received: 19.10 .2019

Accepted: 04.07.2020

A - Work concept and design, B - Data collection and analysis, C - Responsibility for statistical analysis, D-Writing the article, $\mathbf{E}$-Critical review, $\mathbf{F}$ - Final approval of the article 